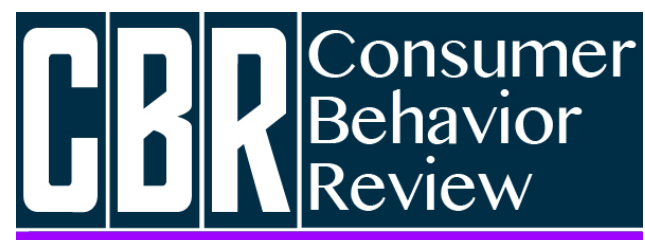

Revista Comportamento do Consumidor
Lira, J. S., Silva Júnior, O. G., \& Costa, F. Z. N. (2020). Como se dá o Engajamento do Consumidor em um Espaço Colaborativo: Relação de negócios ou devoção? Consumer Behavior Review, 4(1), 53-65.
ISSN: 2526-7884

Editor: Prof. Dr. Marconi Freitas da Costa Journal's e-mail: cbr@ufpe.br
Evaluation: Double blind review

Received: 10 de outubro de 2019

Accepted: 26 de janeiro de 2020

\title{
COMO SE DÁ O ENGAJAMENTO DO CONSUMIDOR EM UM ESPAÇO COLABORATIVO: RELAÇÃO DE NEGÓCIOS OU DEVOÇÃO?
}

How does consumer engagement take place in a collaborative space: business relationship or devotion?

\author{
Jordana Santos de Lira ${ }^{1}$ \\ ORCID: https://orcid.org/0000-0002-1707-2153 \\ E-mail: jordanaslira@hotmail.com \\ Omero Galdino da Silva Júnior ${ }^{1}$ \\ ORCID: https://orcid.org/0000-0003-1778-9258 \\ E-mail: omerogaldino@gmail.com \\ Flávia Zimmerle da Nóbrega Costa ${ }^{1}$ \\ ORCID: https://orcid.org/0000-0002-9210-7889 \\ E-mail: flaviazimmerle@hotmail.com
}

\begin{abstract}
${ }^{1}$ Programa de Pós-Graduação em Gestão, Inovação e Consumo - PPGIC, Universidade Federal de Pernambuco, Caruaru, Brasil
\end{abstract}

\begin{abstract}
Resumo
Considerando a naturalização do papel produtivo do consumidor a partir das mudanças causadas pelas tecnologias digitais, o presente estudo teve como principal objetivo analisar como se dá o engajamento dos empresários de pequenos negócios com um espaço colaborativo, do qual fazem parte, no interior de Pernambuco. Assim, a partir desse estudo de caso instrumental buscou-se compreender como esses clientes de serviços significam a sua relação com essa empresa. Para isso, foram
\end{abstract}

\begin{abstract}
Considering the naturalization of the consumer's productive role based on the changes caused by digital technologies, the present study had as main objective to analyze how small business entrepreneurs engage with a collaborative space, of which they are part, in the interior of Pernambuco. Thus, from this instrumental case study, we sought to understand how these service customers mean their relationship with this company. For this, a bibliographic research and a field research were carried out, collecting the data through
\end{abstract}


realizadas uma pesquisa bibliográfica e uma pesquisa de campo, coletando-se os dados por meio da entrevista aberta e da observação não-participante. Nessa pesquisa de cunho qualitativo, utilizou-se o método da análise de discurso funcional. Os resultados apontaram que a cocriação dos expositores na relação com a empresa é bastante expressiva, sendo, contudo, significada por eles como um ato de devoção e gratidão para com a empresa.

Palavras-chave: Engajamento do Prossumidor; Espaço Colaborativo; Significação da Relação; Prossumerização. the open interview and non-participant observation. In this qualitative research, the functional discourse analysis method was used. The results showed that the co-creation of the exhibitors in the relationship with the company is quite expressive, being, however, meant by them as an act of devotion and gratitude to the company.

Keywords: Prosumer engagement; Collaborative Space; Relationship Meaning; Prosumerization.

Esta obra está licenciada com uma Licença Creative Commons Atribuição 4.0 Internacional.

\section{INTRODUÇÃO}

$\mathrm{Na}$ era da informação, a quantidade de dados que circulam na Internet extrapola consideravelmente o volume de conhecimento que tínhamos armazenado em espaços físicos nas décadas anteriores. Atualmente, sabe-se que o usuário é bombardeado a cada segundo por novas fontes de informação e, com isso, marcas também aproveitam esses canais para reforçar suas presenças (Kotler, Kartajaya \& Setiawan, 2017). Surge, assim, a necessidade de aprofundar a compreensão da adesão e da potencialidade do comportamento do consumidor nesse cenário, bem como de alguns conceitos e entendimentos acerca da prática e do próprio papel do marketing no ambiente digital.

Hoje, os usuários das redes sociais digitais são reconhecidos como produtores de conteúdo gratuito e voluntário acerca de qualquer assunto pelos quais se interessem, o que os torna provedores de informação, um papel antes apenas desempenhado pela mídia (Shirky, 2011) e, até certo ponto, seus conteúdos eram controlados pelos canais de emissão. Por sua vez, recentes percepções da teoria crítica social defendem que consumo e produção constituem-se mutuamente, portanto, propõem que as análises considerem a integração entre as esferas de produção e consumo (Bücher \& Igoe, 2013; Ruckenstein, 2015).

Dessa forma, uma das possibilidades de conhecer os desejos e as capacidades do consumidor e de entender a relação entre esses e os produtores é por meio do conceito de prossumerização (Ritzer, 2015a). 0 termo se refere ao processo inter-relacionado de produção e consumo, considera que um necessariamente envolve o outro, sendo impossível distingui-los. Seguindo Ritzer (2015b), a decisão de analisar a produção "pura" ou o consumo "puro" equivale a uma possibilidade teórica mas a uma impossibilidade empírica, podendo implicar no obscurecimento da compreensão de um fenômeno.

A disseminação do uso da internet potencializou o processo de prossumerização, abrindo espaço para que, cada vez mais, os consumidores se comuniquem e envolvam com as marcas e cocriem valor para os produtos e os serviços com que se envolvem (Büscher \& Igoe, 2013). O consumidor passou a ser respeitado como um agente potencialmente ativo nessa relação, tornando-se um prossumidor, isto é, um consumidor proativo e prospectivo, que se envolve diretamente no desenho, na execução, no desenvolvimento e na elaboração de um produto ou serviço, gerando, ele mesmo, valor (Ritzer, 2015a).

Assim, este prossumidor é criador e disseminador do conteúdo das marcas, ao mesmo tempo em que consome seus produtos e informações, esse agente promoveu mudanças estruturais nos modos de relacionar-se com as empresas. Agora tornou-se preciso entender como se comunicar de forma mais eficaz com esse público. Ainda, de acordo com Kotler et al. (2017), os clientes não são mais categorizados em segmentos: eles estão socialmente agrupados e conectados em comunidades por 
identificação com os produtos ou serviços. As empresas, portanto, para terem acesso a comunicação com seu público-alvo precisam pedir permissão para adentrar nesses grupos e entender as mecânicas envolvidas.

É preciso entender que "as comunidades de consumidores estão imunes a spams e às propagandas irrelevantes" (Kotler et al., 2017, p. 64). Portanto, algumas das formas de comunicação existentes nas práticas do marketing tradicional já não se aplicam mais ao marketing digital, demandando dos profissionais dessa área uma versatilidade jamais vista para tratar com tal relação.

Desse modo, o reconhecimento pelas empresas desse potencial colaborativo do consumidor aliado ao fato de que existe neles um desejo latente em participar mais ativamente com as coisas pelo que se interessam, despertou o interesse do marketing. Os profissionais de marketing buscam escutar as experiências de clientes com produtos e serviços, dispor de seus conhecimentos, de sua capacidade criativa e de seu poder de influência sobre seus grupos de referência. Essa forma de relação colaborativa tem sido incentivada não apenas com os consumidores finais de produtos ou serviços, mas também entre parceiros de negócios, colaboradores internos e fornecedores em geral. As empresas se preocupam em com envolver e motivar a prática de prossumidores, buscando conquistar seu engajamento com os produtos ou serviços que ofertam (Carvalho, 2012).

Portanto, podemos entender que uma das palavras-chaves para o reforço dessa capacidade produtiva é, portanto, o engajamento do cliente, cuja conquista é percebida a partir do envolvimento desse com a empresa. Porém, as lógicas dos relacionamentos e modos de troca não comerciais na economia colaborativa da rede consumidor-produtor são complexas e diversas (Scaraboto, 2015). Parmentier e Ficher (2015), por exemplo, analisam que relacionamento e engajamento são conceitos muito distintos, uma vez que relacionar-se não implica em engajar-se. Diante disso nos questionamos como a estratégia de envolver o consumidor com intuito de engaja-lo com a marca, para que ele contribua com a criação e transmissão de seus valores (e não, ao contrário, os deturpe ou até os destrua completamente) realmente funciona. Nesse sentido, o estabelecimento da relação entre clientes e uma loja colaborativa é um contexto exemplar onde isso pode ser estudado.

O Sebrae (2019) define a loja colaborativa como sendo "um modelo de negócio fundamentado nos princípios da economia colaborativa que, por sua vez, nada mais é que o compartilhamento e a troca de serviços e objetos entre empresas", em geral efetuado em um ponto comercial partilhado, que é gerenciado pela equipe ou pelo proprietário do espaço físico. O Sebrae considera essa uma alternativa vantajosa para os empresários de pequenos negócios, uma vez que esses dividem o espaço físico (por vezes com outros diferentes segmentos de produtos), diminuindo os custos fixos, possibilitando a criação de parcerias entre os negócios e gerando o aumento do fluxo de clientes, pela comodidade de encontrar no mesmo espaço um mix diverso de produtos; inclusive, segundo o Sebrae, esse fator pode propiciar sua fidelização.

Selecionamos para nosso estudo de caso uma loja colaborativa considerada pioneira nesse modelo de negócios no Agreste de Pernambuco. Os participantes desse modelo de negócio são recorrentemente incentivados à cocriação. Por meio das plataformas digitais, especialmente o Instagram, os proprietários estimulam seus expositores a participarem e cocriarem conteúdo junto à empresa, dando forma a essa relação. Por meio de enquetes e comentários no Instagram, os clientes assumem o papel de prossumidores, uma vez que produzem conteúdo que será utilizado pela empresa para melhor atendê-los. A cocriação também acontece no espaço físico da mesma. 0 maior exemplo de cocriação pode ser vista na participação da montagem e escolha da vitrine da semana, em que esses expositores votam nas enquetes e participam deixando comentários de como gostariam que a vitrine fosse montada.

Considerando que na era do "capitalismo prossumidor" (Ritzer, 2015b) as relações entre consumidores e fornecedores de produtos e/ou serviços assumiram novas características, a pesquisa objetivou compreender os sentidos dados pelos expositores à sua relação com a loja colaborativa que gerencia e fornece o espaço comercial para o grupo. Desse modo, o artigo pretendeu responder: Como os consumidores de serviços de uma loja colaborativa significam a sua relação com a marca?

Assim, ao analisarmos como esses consumidores de serviço atribuem sentidos para sua relação com a marca, podemos apontar possíveis caminhos para entender como os mesmos se envolvem e engajam para produzir e disseminar valores. Acreditamos que os nossos resultados 
contribuam com os estudos do consumidor, não apenas no entendimento do fenômeno (a relação criativa e colaborativa incentivada entre parceiros de negócios), mas indique caminhos para explorar a relação do engajamento do prossumidor com a marca, apresentando informações de como acontece esse processo na era digital; tais insights que podem gerar conhecimento tanto para a comunidade acadêmica como para os profissionais da prática gerencial.

\section{REFERENCIAL TEÓRICO}

\section{A cultura participativa na era digital}

A forma e a rapidez com que as informações circulam nos meios sociais mudou o cenário dos mercados. Com a internet, a agilidade e alcance que a informação atinge tendem a potencializar as experiências de consumo. 0 cenário de prossumerização, em que as esferas de produção e consumo são vistas como integradas (Bücher \& Igoe, 2013; Ritzer, 2015a; Ritzer, 2015b; Ruckenstein, 2015), evidencia como a agência do prossumidor modificou completamente a estrutura das formas de relação entre o cliente e a empresa.

Consumindo e, ao mesmo tempo, produzindo, esses indivíduos constituem o que se conhece por cultura participativa. Segundo Jenkins (2008) a Web 2.0 possibilitou a aproximação entre indivíduos por meio dos sites de redes sociais, criando laços fortes e fracos no mundo digital. A democratização dos espaços e a possibilidade de atuação nos mesmos incentiva cada vez mais a adoção desses canais por novos membros fortalecendo essa cultura participativa e criando as potenciais comunidades de consumo. Por conta disso, Jenkins (2008) analisa que, caso não se estabeleçam nas regras próprias dessa cultura, os produtores tendem a ser menos procurados por seus clientes e até esquecidos, uma vez que eles estão ávidos a se relacionarem por meio de suas redes sociais virtuais. Para isso, as organizações precisam entender que são apenas atores nesses espaços midiáticos e não mais detêm o controle total da emissão da informação (Jenkins, 2008).

Podemos entender que a sobrevivência dos negócios nos meios digitais requerem reconhecer e saber como fazer o melhor uso da capacidade criativa e do poder de influência dos prossumidores sobre seus grupos de referência, uma vez que, nesse meio, a empresa não possui quase nenhum controle sobre os valores ou informações ali geradas que são rápida e amplamente divulgadas. Por outro lado, podemos dizer que as experiências de consumo são cruciais para a construção das identidades dos consumidores e para sua atuação nesse cenário considerado como um continuum de produção e consumo (Costa \& Souza-Leão, 2019). Mas como, numa cultura participativa já instaurada, a relação entre as marcas e seus consumidores podem ser benéfica para ambos nesse processo?

Inicialmente é preciso reconhecer a capacidade produtiva do consumidor nesse meio e entender como ela se dá. 0 que vislumbramos é que, na era da informação, envoltos em uma forma social cada vez mais voltada para o consumo, métodos convencionais de marketing parecem ter perdido força frente às novas abordagens mais participativas. Num ambiente em que cada vez mais o conhecimento e as informações são buscados pelas pessoas em canais democráticos e entendimentos são construídos colaborativamente, portanto, provenientes de fontes menos unilaterais, o modo de criação e promoção de valor efetuado pelo modelo clássico do marketing foi seriamente afetado. Carvalho (2012) afirma que as empresas reconhecem os prossumidores como colaboradores, investem em ambientes virtuais mais interativos e se preocupam em motivar a participação desses agentes, recompensando suas ações e buscando conquistar seu engajamento com a marca. Afinal, são nos processos de troca simbólica que os significados são atribuídos aos bens de consumo (McCracken, 2003).

Nesse sentido, entendendo que essa forma de relação mais colaborativa vem sendo incentivada na prática empresarial de forma ampla, ou seja, passou a envolver também os parceiros de negócios e os fornecedores em geral (Carvalho, 2012), nos questionamos como, em um modelo de negócio já fundamentado nos princípios da economia colaborativa, vem sendo efetivado o engajamento dos clientes, ou seja, como essa relação se estabelece e é operacionalizada? 


\section{Lojas Colaborativas}

Novas formas de produzir e de consumir vem ganhando força nos mercados após o crescimento de preocupações a respeito da preservação do meio ambiente aliado ao consumo excessivo, uma lógica própria e totalmente enraizada em nossas formas de sociedades (Silva et al., 2020). Em paralelo à criação pelos clientes de novos modos de consumir, vem sendo implementadas novas formas de produzir e de criar parcerias, visando, em um contexto microeconômico, impactar a economia e criar espaços onde a colaboração seja estimulada (Botsman \& Rogers, 2011).

Nos Estados Unidos, por exemplo, no fim dos anos 1990, algumas iniciativas incipientes despontam, sendo chamadas de garage sales, em que aconteciam as vendas de produtos usados em garagens ou quintais (Markus \& Orsi, 2016). Apesar de no exterior esse modelo de empresa embasado em princípios colaborativos não ser novidade, recentemente no Brasil ele despontou como uma tendência que "privilegia a diversidade e os pequenos artesãos e produtores" (Costa, Alcade, \& Souza, 2018, p. 1219). Atualmente, já observamos iniciativas mais amplas nesse sentido no país, ligando a tecnologia a aspectos da colaboração de forma mais comum, como no caso de aplicativos de caronas (Menezes, 2018; Souza Júnior, 2018), comunidades virtuais de trocas de tempo (Costa \& Falcão, 2018) e compartilhamento de bicicletas (Silva \& Barbosa, 2018).

Para Wood e Gray (1991, p. 146) o contexto colaborativo se dá "quando um grupo de stakeholders assume autonomia para se engajar na resolução de um problema em um processo interativo com regras compartilhadas, normas e estruturas". Nessa lógica, as lojas colaborativas surgiram e tornaram-se cada vez mais numerosas no mundo e nos cenários locais, pois são vistas pelos empreendedores como vantajosas, uma vez que auxiliam micro e pequenos empresários a ter mais visibilidade, cooperação e compartilhamento de riscos em um cenário de negócios competitivo (Sebrae, 2019).

As lojas colaborativas constituem, assim, um espaço físico coletivo, em que se pode comercializar produtos e serviços de diferentes segmentos, usufruindo as vantagens de um espaço comercial com um menor investimento de recurso, pois os custos de manutenção, aluguel, divulgação, promoção, entre outros, são compartilhados. Nesse espaços, em geral, se investe em canais virtuais de comercialização, atendimento a domicílio e se abre possibilidades de parcerias e networking entre os expositores que dele participam (Sebrae, 2019).

Costa et al. (2018) aponta que o proprietário-gestor do espaço deve oferecer serviços de consultoria visando identificar possíveis falhas na gestão, na prestação do serviço e/ou na qualidade dos produtos ou serviços, com intuito de auxiliar seus clientes nesses aspectos, além de fomentar um ambiente democrático em que a coletividade e a colaboração sejam conceitos efetivamente praticados; desse modo as experiências são sempre aprimoradas e se prestam ao crescimento coletivo.

Apesar do modelo das lojas colaborativas estarem se multiplicando no Brasil, Costa et al. (2018) identificam uma carência de pesquisas na literatura acerca de seu modelo de negócios. 0 gap nas pesquisas perpassa por várias áreas da gestão, incluindo o modo como acontece essa ação colaborativa, especialmente quando se trata da perspectiva de micro e pequenas empresas (Phillipson, Gorton \& Laschewski, 2006).

\section{O caso de nosso estudo: a X Loja}

A presente pesquisa se debruçar sobre o caso de uma Loja Colaborativa situada no Agreste de Pernambuco. Visando preservar sua identidade nominamos a mesma de X Loja. Iniciando suas atividades em maio de 2017, a X Loja é considerada a primeira com esse formato de negócios a estabelecer-se no interior de Pernambuco. A mesma anuncia, como o seu principal objetivo, fomentar o empreendedorismo local e criativo da região. Assim, tem por missão ser uma loja colaborativa, diversa e solidária, que fomenta uma rede sustentável de incentivo e apoio ao empreendedorismo local ao propiciar um ambiente econômico para o desenvolvimento de negócios locais.

Inicialmente, a X Loja contava apenas com espaço comercial colaborativo, contudo, atualmente é considerada uma marca guarda-chuva para três negócios de base colaborativa que compartilham o mesmo espaço: a X Loja Colaborativa, a X Café e a X Coworking, tornando-se, deste modo, o primeiro complexo colaborativo do interior de Pernambuco. 
A X Loja nomina os pequenos(as) empreendedores(as) que dela participam de Singulares. Esses comercializam os seus produtos e serviços com as vantagens de uma loja física bem equipada, sem precisarem investir recursos em um ponto comercial próprio. 0 espaço é visto como um ambiente de fomento ao empreendedorismo uma vez que oferece um pacote de serviços com intuito de dar suporte para quem está começando. 0 espaço abre o atendimento aos consumidores na forma presencial, além de fazer a divulgação de todos os produtos na mídia social da empresa, logrando maior visibilidade às marcas desses pequenos empreendedores. Atualmente, a X Loja conta com mais de 80 marcas de Singulares expondo em seu espaço.

A X Café também é um espaço colaborativo de fornecedores alimentícios, isto é, pequenos empreendedores que têm seus produtos alimentícios expostos e comercializados no espaço do café, funcionando do mesmo modo que a loja colaborativa. A X Café oferece o Clube de Leitura, uma estante de livros (recebidos por doação), que podem ser trocados por outros ou tomados emprestados para leitura; no Clube ainda existem um grupo de livros raros disponibilizados pelo Instituto Histórico de Caruaru, esses apenas para consulta no local.

A X Coworking, por sua vez, é o serviço mais recente disponibilizado pela X Loja e foi criado para atender às demandas de profissionais liberais, autônomos ou mesmo de estudantes que necessitam de um espaço profissional e que, por muitas vezes, não possuem condições financeiras para alugar um escritório particular. A X Coworking oferece ainda salas de reunião privativa e um auditório para recepcionar eventos.

Contudo, como é próprio desse modelo, é fundamental que os expositores se adequem ao dinamismo do negócio (Costa et al., 2018) e que se envolvam com a produção de valor, com as decisões administrativas coletivas, e que sejam propositivos e criativos no enfrentamento dos problemas coletivos.

\section{0 marketing e o engajamento}

Alguns estudos a respeito do engajamento dos consumidores se desenvolveu em comunidades de marca, e trouxe a perspectiva desses sujeitos como prerrogativa para análise do discurso dos então categorizados fãs. Contudo, em geral, a visão do marketing volta-se para o entendimento de como utilizar o envolvimento dos indivíduos com um produto ou serviço como uma forma de influenciar suas decisões de compra. As dicas se voltam para encantar e fidelizar os clientes, disponibilizando atendimento vip, sempre acompanhado de um monitoramento focado para garantir a ação de "um exército de porta-vozes para sua marca" (Endeavor, 2019). Nesse sentido, considerando a forma das relações na cultura participativa, Jenkins (2008, p. 97), critica o entendimento linear da relação, dado pela "necessidade de quantificar o desejo, de mensurar as relações e de transformar o envolvimento em commodities - e, talvez o mais importante, a necessidade de transformar tudo o que foi mencionado acima em retorno financeiro".

Contudo, foi a ascensão de uma nova figura não entendida mais como passiva no final do processo produtivo, que desestabilizou as previsões dos estudiosos da área de marketing, que passam a reconhecer um consumidor mais poderoso e com capacidades indiscutíveis de criação (Mazetti, 2009). Um problema que se percebe é o de como envolver esse prossumidor e engajá-lo num trabalho produtivo de valor que beneficie as marcas em um ambiente cada vez mais volátil?

Recentemente, o conceito de engajamento tem sido amplamente discutido em áreas como Sociologia, Psicologia e Comportamento Organizacional, apesar de não ser tão novo o seu emprego, uma vez que sua primeira aplicação data do século XVII (Brodie, Hollebeek \& Smith, 2011). Estudiosos acreditam que o termo evoluiu na atualidade para um envolvimento emocional mediado pela participação. A ação move um comportamento de consumo caracterizado pela interação social com grupos, marcas ou ideais (Damacena, Marra \& Petroll, 2012). Nesse sentido, Brodie et al. (2011) reiteram que o engajamento do cliente com a marca geralmente se dá por meio de um "estado psicológico" facilitado em um ambiente permissivo para a cocriação, que se apresenta sensível às experiências dos clientes.

Contudo, dentre as discussões que envolvem o termo engajamento, Patterson, Yu e Ruyter (2006) indicam, a existência de quatro pilares que sustentam essa prática na perspectiva do 
marketing: (i) a absorção, que se refere à capacidade de aderência em um nível cognitivo ao processo de envolvimento do cliente; (ii) a dedicação, a qual inclui a característica mais emocional da cocriação de valor e o senso de pertencimento à marca; (iii) o vigor, aspecto mais energético e direcionado para a ação de interatividade com a marca; e (iv) a interação, que trata da comunicação aberta entre os dois sujeitos em questão: marca e prossumidor.

Assim, podemos entender que é, a partir da capacidade de interação e do envolvimento emocional do cliente com a empresa, que surgem os fundamentos para entender a questão do engajamento e que hoje esse entendimento pode ser considerado fundamental para a prática do marketing.

\section{PROCEDIMENTOS METODOLÓGICOS}

A nossa pesquisa realizou um estudo de caso qualitativo. 0 método qualitativo busca compreender como se dá determinado fenômeno e quais as suas implicações para os sujeitos de pesquisa, apoiados em uma visão mais holística do processo de investigação do social (Bauer \& Gaskell, 2002).

Stake (2006) defende que o estudo de caso pode ser de três tipos: a) o estudo de caso coletivo, em que um conjunto de casos pode responder acerca de determinado fenômeno; b) o estudo de caso intrínseco, cujo interesse da pesquisa é a sua própria singularidade; e c) o estudo de caso instrumental, onde encontra-se nosso estudo; nesse o caso é escolhido não apenas por representar outros casos, mas por sua capacidade de gerar novos aprendizados, potencializando associações e transferência de descobertas para outros contextos, assim fazendo avançar o conhecimento.

0 caso instrumental escolhido para o estudo foi uma loja colaborativa situada no Agreste pernambucano. Nossa escolha deveu-se ao fato desse ser um modelo de negócios cuja implementação é relativamente nova, sua divulgação está em alta, mas ainda poucos estudos se voltaram para esse modelo de negócios (Costa et al., 2018; Phillipson et al., 2006). Como seu funcionamento pressupõe o estabelecimento de uma estreita rede de colaboração entre os clientes e entre eles e o fornecedor do serviço, torna-se portanto, um modelo que pode gerar valiosos insights acerca de como acontece o engajamento do prossumidor. Para além disso, essa loja foi a pioneira no estabelecimento de tal modelo de negócios na região, sendo importante entender sua operacionalização.

Nosso corpus foi formado pelo discurso de sete singulares (empresários de pequenos negócios expositores dessa loja colaborativa). A coleta dos dados se deu por meio de duas técnicas de pesquisa: a entrevista aberta, que permite um intercâmbio de ideias entre pesquisador e participante; e a observação não-participante, utilizada como forma de obter detalhes simbólicos importantes que, apesar de materializados por gestos, tom de voz etc., não foram diretamente verbalizados pelos respondentes na aplicação da entrevista (Godoi \& Bandeira-De-Mello, 2006). 0 uso de mais de uma maneira de coletar os dados gera confiabilidade à pesquisa qualitativa, por sua capacidade em corroborar com as evidências e consequências do fenômeno estudado (Zappellini \& Feuerschütte, 2015). O roteiro da entrevista foi formado por seis tópicos direcionadores que versaram acerca de como esses agentes entendem (e atribuem sentidos) à sua relação comercial com a Loja; a entrevista iniciou-se com a seguinte pergunta: o que essa loja colaborativa representa para você?

Por fim, a análise de discurso funcional (Gill, 2002) foi a estratégia escolhida para análise dos dados. Gill (2002) aponta que, para dar conta das diferenças entre os vários tipos de análise de discursos existentes, deve-se pensar em tradições teóricas mais amplas. Para tanto, a autora indica a existência de três tradições: a) a tradição mais comprometida com a semiótica e a análise estruturalista; b) a tradição mais associada ao pós-estruturalismo; e c) a tradição influenciada pelos atos de fala e pela etnometodologia, onde encontra-se nossa análise. Essa tradição se interessa por destacar a orientação funcional do discurso, ou seja, busca revelar o que as narrações tem por objetivo conquistar em determinada interação ou contexto discursivo; essa questão se sobrepõe em importância às observações de como esse discurso se relaciona com o mundo.

Inspirados em Gil (2008), nossa análise obedeceu a três etapas: a) agrupamento e simplificação dos dados por temas, efetuada de modo a possibilitar a análise do inter-relacionamento entre esses, suas semelhanças e suas diferenças - nessa etapa organizamos o conjunto dos dados por 
categorias, as quais nominamos de atividades discursivas; b) buscamos levantar quais funções ou ações estiveram presentes no contexto discursivo de cada uma das diversas narrações que compuseram as categorias ou atividades; por fim, a partir das linhas de significados geradas nas relações levantadas, c) buscamos desvelar os significados, as regularidades e os padrões encontrados, trazendo à tona o sentido gerado por essa triangulação.

\section{Organização do corpus}

Como primeira etapa analítica, o conjunto dos dados foi organizado em categorias (Gil, 2008). Para essa organização consideramos as temáticas gerais tratadas nas falas dos respondentes. 0 Quadro 1 apresenta as cinco categorias a que chegamos:

\begin{tabular}{|l|l|}
\hline \multicolumn{1}{|c|}{ Atividades } & \multicolumn{1}{c|}{ Descrição } \\
\hline $\begin{array}{l}\text { Relacionamento } \\
\text { sólido }\end{array}$ & $\begin{array}{l}\text { Os singulares consideram possuir uma relação sólida com a Loja, uma } \\
\text { relação que caracterizam como parceira e que envolve amizade, } \\
\text { reciprocidade, colaboração, que gera visibilidade, segurança e aprendizado. }\end{array}$ \\
\hline $\begin{array}{l}\text { Cultura } \\
\text { organizacional- } \\
\text { familiar }\end{array}$ & $\begin{array}{l}\text { A relação de colaboração constantemente incentivada pela Loja, tanto para } \\
\text { as decisões administrativas quanto para as estratégias de vendas, os faz se } \\
\text { sentir um grupo; os singulares acreditam que tal relação torna o ambiente } \\
\text { mais seguro, acolhedor e não competitivo; afirmam se sentir parte de uma } \\
\text { família, pois possuem um objetivo coletivo: fazer crescer as suas marcas. }\end{array}$ \\
\hline $\begin{array}{l}\text { Cocriação } \\
\text { crescimento pessoal }\end{array}$ & $\begin{array}{l}\text { Os singulares são incentivados a participar ativamente da produção de } \\
\text { conteúdo (gerar valores), especialmente para os meios digitais. A relação de } \\
\text { trocas é entendida como promotora de benefícios mútuos, de vantagens } \\
\text { econômicas e solidificadora de uma rede de amizades. Os singulares } \\
\text { reconhecem que aprendem diariamente tanto com a própria Loja quanto } \\
\text { com o relacionamento estabelecido entre eles mesmos. }\end{array}$ \\
\hline Oportunidade & $\begin{array}{l}\text { Para os singulares, a Loja é vista como uma oportunidade única para os } \\
\text { pequenos produtores; A mesma cuida deles, pois olha para os pequenos } \\
\text { produtores, oportuniza a inserção no mercado, promove vendas e } \\
\text { visibilidade para suas marcas. }\end{array}$ \\
\hline
\end{tabular}

Fonte: Elaborado pelos autores (2019).

Quadro 1. Atividades discursivas

\section{ANÁLISE E DISCUSSÃO DOS RESULTADOS}

Dando sequência à análise, a segunda etapa analítica buscou revelar as funções de cada narrativa no interior do seu grupo de atividade. 0 Quadro 2 apresenta as três funções encontradas nesse campo discursivo.

\begin{tabular}{|l|l|}
\hline \multicolumn{1}{|c|}{ Funções } & \multicolumn{1}{c|}{ Descrição } \\
\hline $\begin{array}{l}\text { Reconhecer a } \\
\text { importância }\end{array}$ & $\begin{array}{l}\text { Diz respeito à ação discursiva efetuada para admitir a relevância da Loja e de } \\
\text { seus serviços para o crescimento e sobrevivência de seus negócios. }\end{array}$ \\
\hline $\begin{array}{l}\text { Sentir-se } \\
\text { valorizado/ } \\
\text { amparado }\end{array}$ & $\begin{array}{l}\text { Se refere à ação de expressar um sentimento inclusão e de segurança, dado } \\
\text { pelas recorrentes oportunidades que receberam de aprendizado, para fazer } \\
\text { parte nas decisões coletivas e para participar da cocriação de imagem e de valor } \\
\text { para a Loja e para suas marcas. }\end{array}$ \\
\hline $\begin{array}{l}\text { Sentir-se } \\
\text { confiante }\end{array}$ & $\begin{array}{l}\text { Trata da ação de reconhecer que as relações travadas nesse espaço ensinam } \\
\text { diversas habilidades, motivando e preparando os singulares a serem indivíduos } \\
\text { mais autônomos. }\end{array}$ \\
\hline $\begin{array}{l}\text { Mostrar-se } \\
\text { grato }\end{array}$ & $\begin{array}{l}\text { Se refere a uma ação comum nas falas dos singulares: expressar repetidamente } \\
\text { o seu reconhecimento acerca da importância da Loja também para suas vidas, } \\
\text { estímulo diante de problemas e ansiedades pessoais. }\end{array}$ \\
\hline
\end{tabular}

Fonte: Elaborado pelos autores (2019)

Quadro 2. Funções 
As relações encontradas entre as atividades discursivas e as funções nos ajudaram a entender o sentido dado pelos singulares à sua relação com a Loja. Essas relações estão apresentadas na Figura 1 .

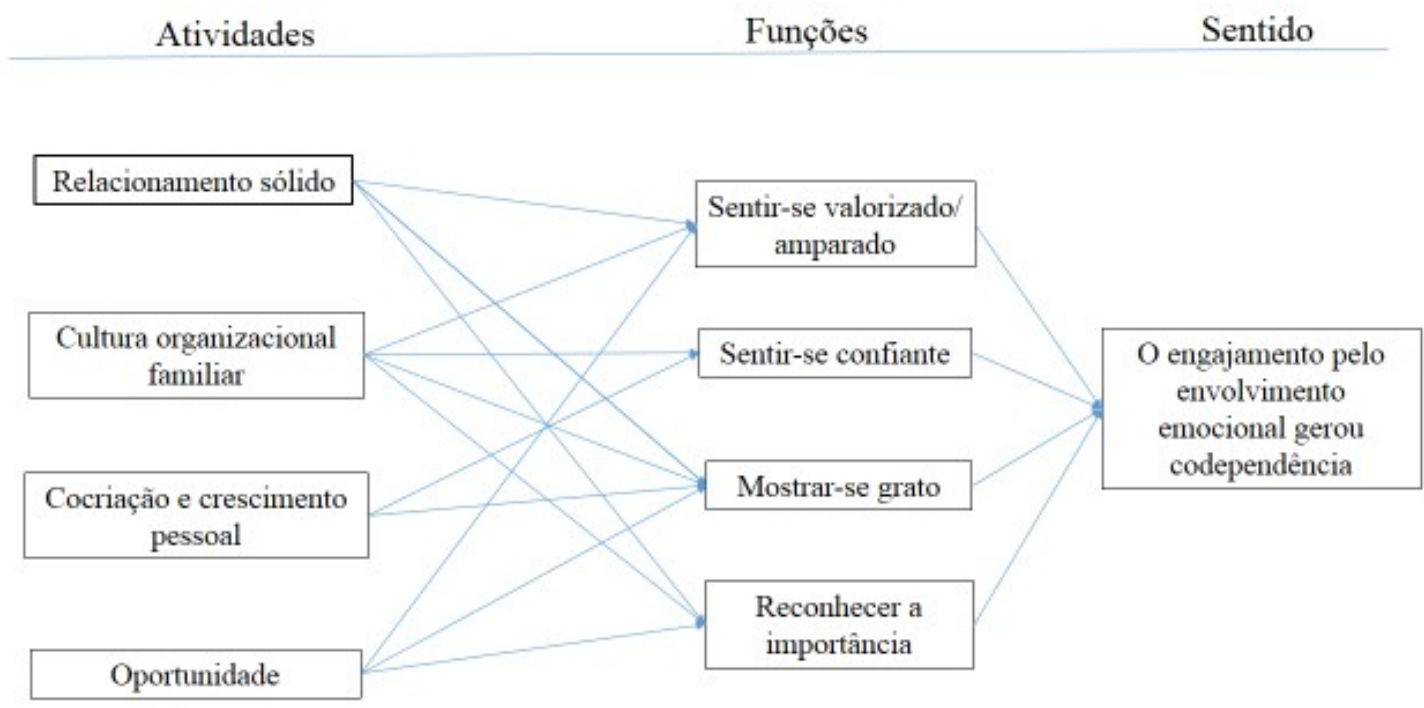

Fonte: Elaborado pelos autores (2019).

Figura 1. Relações entre atividades, funções e sentido em relação à loja X.

Como primeiro ponto da análise, observamos que todas as atividades tiveram por função mostrar-se grato. Essa questão foi recorrente nas falas de todos os entrevistados. Por sua vez, a única atividade que se apresentou vinculada a todas as funções foi a cultura organizacional-familiar. As referência à cultura dessa comunidade surgiram nesse contexto com a finalidade de indicar os sentimentos de valorização, confiança, gratidão e reconhecimento da importância. Isso aponta para o bom funcionamento do ambiente colaborativo, ao mesmo tempo em que indica que a gestão da X Loja tem cumprido um papel relevante para seus expositores. Seguindo Costa et al. (2018) o serviço do gestor-proprietário deve fomentar a criação de tal ambiente de colaboração para que as experiências e o crescimento do grupo sejam aprimoradas.

A questão da cultura organizacional-familiar com a função de reconhecer a importância e mostrar-se grato pode ser ilustrada pelo trecho de fala:

\#E1 - A X Loja faz muito mais do que a obrigação que possui, incentiva muito os singulares a participarem e cocriarem; muitos não tem tempo, então a X Loja faz muito mais pelos singulares do que os singulares pela X Loja.

A atividade discursiva Relacionamento Sólido se apresentou vinculada a três funções no contexto das entrevistas. Os trechos de fala a seguir ilustram como se deu as linhas de significação entre a atividade e as funções: sentir-se valorizado/amparado e reconhecer a importância da relação. Ao ser questionado o que a X Loja representa para você, os entrevistados responderam:

\#E5 - Segurança. Uma relação de troca com benefícios múltiplos.

\#E6 - Segurança. São amigos acessíveis.

\#E7- A X Loja foi a minha primeira oportunidade de expor meus produtos; [...] há uma relação de apoio e cooperação e eu me sinto realizada lá.

Contudo, o relacionamento sólido com a X Loja demonstra realização pessoal, mas não apontou por função o sentir-se confiante, ou seja, em nenhuma das falas houve a intenção de demonstrar como 
esse relacionamento considerado sólido os torna mais autônomos em seus negócios. Wood e Gray (1991) analisam a importância da autonomia no contexto colaborativo para o engajamento dos participantes e a busca de soluções criativas. Nas falas dos entrevistados a função sentir-se confiante apareceu nas atividades da cultura e da cocriação para o crescimento pessoal. A questão levanta a possibilidade de que os singulares, apesar de reconhecerem a importância da X Loja em seus negócios e mostrarem sua gratidão para com a mesma, atribuam seu crescimento às relações com o grupo como um todo. Os exemplos abaixo apresentam melhor a questão:

\#E1 - A X Loja representa a colaboração de fato! Você não vê competição, mas colaboração.

\#E3 - [...] há realmente cooperação e não competição.

\#E4 - Há uma relação entre negócios primeiramente, mas depois disso representa uma relação de amizade, de cooperação, uma corrente de empatia e parceria.

Acreditamos que entender que a X Loja como parte do coletivo novamente aponte para o bom funcionamento do ambiente colaborativo da gestão, mas a função de gratidão que aparece em todas as atividades preocupa. Entender os gestores da X Loja como parte da família e do coletivo e essa relação significar segurança, pode ser um indício de dependência e acomodação e isso enfraquecer o aprendizado e diminuir a autonomia. Os entrevistados verbalizam esse sentimento quando se trata da atividade oportunidade com a função de mostrar-se grato:

\#E2 - Eles parecem psicólogos quando se chega de cabeça baixa. [...] se tornaram parte da família [...] a relação é de acolhimento.

\#E3 - Tenho a sensação de gratidão por ver que outras pessoas estão enxergando minha marca.

\#E4 - Fazem parte da X Loja, considerando como se ela fosse deles ou da família.

Como no Brasil participam mais desse modelo pequenos artesão e produtores (Costa et al., 2018), e em nossas entrevistas eles superestimam o fato de que a $X$ Loja "deu oportunidade aos pequenos empreendedores" (\#E3), seria interessante buscar um entendimento mais aprofundado da questão da autonomia versus dependência, uma vez que esse é considerado um fundamental para o amadurecimento do produtor e do próprio modelo de negócios, promovendo o crescimento coletivo.

Costa et al. (2018) indicam também a importância dos expositores se envolverem com a produção de valor e as decisões administrativas coletivas. Por meio da atividade cocriação para o crescimento pessoal com as funções mostrar-se grato e sentir-se confiante, respectivamente) isso foi observado na fala de todos os entrevistados:

\# E2. A X Loja está sempre engajando a gente nas suas ações, eles são muito criativos, isso faz a gente ficar motivado em participar.

\#E6 - Participo de todas as ações que a X Loja faz, cocriando junto com a empresa.

Desse modo existência do envolvimento foi apontada pelo grupo; os singulares reconhecem que aprendem muito ao se engajar nas atividades promovidas pela X Loja, tanto em termos do negócio, quanto em termos pessoais:

\# E2 - [...] quando eu entrei eu não sabia nem gravar um vídeo agora sou quase uma blogueira, (risos) [...] Eu consegui desenvolver outras habilidades que eu não tinha [...].

\#E4 - Houve muito aprendizado sobre a economia criativa e colaborativa.

Os gestores do espaço conquistaram o respeito dos expositores por meio da ampla e constante oferta de serviços, os envolvendo e conquistando a colaboração e o aprendizado. Contudo, apesar de terem tido sucesso no fomento ao ambiente colaborativo e democrático (Costa et. al., 2018) e também no crescimento pessoal e profissional, a importância da autonomia, elemento fundamental para um engajamento mais efetivo (Wood \& Gray, 1991), não parece ter sido ainda amadurecida no grupo. Foi possível perceber uma codependência na relação com a X Loja. Entendemos que seja possível que essa se dê por meio dos fortes vínculos emocionais criados. 0 apoio emocional para questões pessoais e 
profissionais acontecem misturados, gerando uma forte apego à empresa; os singulares acreditam que essa seja uma oportunidade única para seus negócios e para sua vida e se sentem em dívida para com a empresa. Os trechos de fala que partem da atividade oportunidade e tiveram por função sentir-se valorizado/amparado, mostrar-se grato e reconhecer a importância, elucidam como isso se dá:

\#E1- Para mim, é um investimento estar lá. Tem mês que eu não vendo nada, mas meu produto está lá sendo visto, para mim é um investimento.

\#E2 - Muita gente nunca teve uma loja, chega lá sem saber de nada e eles dão muito apoio, ajudam a essas pessoas, ensinam, sabe? Pega na mão. Você entra lá e não fica solto, você se sente acolhido por eles.

\#E6 - Eles são a principal fonte de divulgação do me trabalho [...] é uma relação de segurança e comprometimento.

\section{CONSIDERAÇÕES FINAIS}

A pesquisa teve como objetivo identificar o significado que os singulares atribuem a sua relação com sua marca X Loja, buscando gerar possíveis insights para entender como acontece o engajamento do prossumidor. Para alcançar esse objetivo, foram realizadas sete entrevistas no ambiente da empresa que tem um viés colaborativo e convida seus singulares a participarem das decisões da gestão do espaço e também de produzirem conteúdo para os espaços midiáticos de divulgação; prossumidores, em conjunto com o prestador de serviços estabeleceram a cultura organizacional de cocriação.

Desse modo, em um modelo de negócios participativo, foi possível ver como a lógica própria de uma cultura participativa (Jenkins, 2009) está naturalizada nesses espaços, promovendo entendimentos e conhecimentos construídos colaborativamente. Nesse ambiente fica clara a percepção de como o prossumidor modifica a estrutura das formas de relação entre o cliente e a empresa de serviços. Parceiros, esses clientes-produtores de conteúdo gratuito e voluntário são provedores da informação, promovem e divulgam valores positivos tanto para sua marca como o fornecedor de serviços. As vantagens indicadas pelo Sebrae (2018) tais como a visibilidade, cooperação e compartilhamento de riscos em um contexto de negócios competitivo, se mostraram presentes nas falas do grupo, pois foram citadas as parcerias e o networking criados entre os expositores.

Concluímos que o engajamento de clientes num modelo de negócios pautado nos princípios da economia colaborativa se deu por meio do estabelecimento de um estreito vínculo emocional entre a empresa e o grupo de expositores. Tal como afirmam Marra e Damacena (2012) e Brodie et al. (2011) esse vínculo foi promovido pelos estímulos de constantes ações de cocriação dadas em um ambiente se apresentou bastante sensível (até humano, como afirmou E1), às necessidades desses expositores. Reiteramos, portanto, o entendimento dos autores: o engajamento do cliente foi conquistado por meio de um envolvimento emocional mediado pela participação.

Se analisarmos com base nos quatro pilares que sustentam a prática do engajamento (Patterson et al., 2006), podemos dizer que no grupo estudado houve a absorção, a dedicação e a interação, mas que o vigor, o aspecto mais energético que impulsiona as relações nesse meio, ainda se mostrou pouco desenvolvido. Entendemos que o vigor como um aspecto de força demande uma maior autonomia e propositividade. Imaginamos que um engajamento efetivo do grupo requeira, não apenas que esse se envolva com a produção de valor e as decisões administrativas coletivas, mas que busque saídas inovadoras para o grupo e para o espaço comercial.

Consideramos que, em nosso caso, o sentimento de gratidão percebido nas falas pôde advir do fato de que, para muitos desses pequenos produtores, essa foi a primeira oportunidade de participar de um centro comercial. Contudo, entendemos que tal sentimento não deva ser sentido como uma dívida, tal como surgiu no campo discursivo, mas sim, entendido como um merecimento por seu próprio envolvimento produtivo e criativo. Todos os parceiros nesse modelo de negócios devem ser envolvidos e estimulados para propor soluções inovadoras; a busca por novas saídas para os problemas compartilhados deve ser uma constante em um mercado cada vez mais competitivo. 
Como contribuição, nossa pesquisa aponta para um cuidado nessa relação: o menor envolvimento com problemas pessoais dos expositores participantes dessas redes colaborativas deve ser trabalhado em paralelo ao incentivo pela conquista da autonomia e da consequente e relevante produção criativa de valor. Por sua vez, reiteramos a necessidade de os negócios se posicionarem nos mercados cada vez mais de forma coparticipativa, pois nessa troca simbólica o consumidor se torna imersivo e co-responsável pelos valores da marca.

\section{Referências}

Aguiar, E. C., \& Marques, R. Q. (2016). Comportamento do consumidor e teoria da cultura de consumo: da compreensão dos fenômenos à aplicação do conhecimento. Revista Eletrônica Estácio Recife, $1(1)$.

Arnould, J. E., \& Thompson, C. J. (2005). Consumer Culture Theory [CCT]: Twenty years of research. Journal of Consumer Research, 31.

Arnould, E. J., \& Thompson, C. J. (2005). Introduction: Consumer Culture Theory: ten years gone (and beyond). Consumer Culture Theory, 17(1).

Bauer, M. W., \& Gaskell, G. (2002). Pesquisa qualitativa com texto, imagem e som: um manual prático. Petrópolis: Vozes.

Botsman, R., \& Rogers, R. (2011). O que é meu é seu: como o consumo colaborativo vai mudar o nosso mundo. Bookman: Porto Alegre.

Brodie, R. J., Hollebeek, L. D., \& Smith, S. D. (2011). Engagement: An important bridging concept for the emerging SD logic lexicon. In Proceedings.

Büscher, B., \& Igoe, J. (2013). 'Prosuming' conservation? Web 2.0, nature and the intensification of value-producing labour in late capitalism. Journal of Consumer Culture, 13(3), 283-305.

Carvalho, S. L. (2012). A era do consumidor produtivo. Recuperado em: 03 de fevereiro de 2020 de $<$ https://www.mundodomarketing.com.br/artigos/sergio-lage-carvalho/23899/a-era-doconsumidor-produtivo.html>

Coskuner-Balli, G. (2013). Market practices of legitimization: insights from consumer culture theory. Marketing Theory, 13(2), 193-211.

Costa, F. Z. N., \& Souza-Leão, A. L. M. (2019). A vontade de potência do prossumidor: uma análise da vontade e da força da vontade nas práticas dos potterheads. Revista Eletrônica de Ciência Administrativa, 18(2), 161-193.

Costa, L. A. F., Alcade, E. A., \& Souza, M. L. L. (2018). Lojas colaborativas: conceito, história e montagem. Rev. Conexão Eletrônica - Três Lagoas, MS, v.15, n.1, 1216- 1230.

Costa, D., \& Falcão, R. (2018). O valor percebido pelos usuários na troca de tempo: o caso Bliive. Consumer Behavior Review, 2, 19-32.

Creswell, J. W. (2002). Research design: qualitative, quantitative, and mixed methods approaches. London: Sage Publications.

Damacena, C., dos Santos Marra, G., \& Petroll, M. D. L. M. (2012). Orientação ao mercado, inovação colaborativa com os consumidores e sobrecarga de informação. Perspectivas Contemporâneas, $7(2)$.

Endeavor (2019). Fidelização de clientes: 5 dicas essenciais para encantar o comprador. Recuperado em: 01 de fevereiro de $2020 \mathrm{de}<\mathrm{https}$ ///endeavor.org.br/marketing/fidelizacao-de-clientes/>

Fonseca, M. J., \& Rossi, C. A. V. (1998). O estudo do envolvimento com o produto em comportamento do consumidor: Fundamentos teóricos e proposição de uma escala para aplicação no Brasil. Anais do Encontro da ANPAD, Foz do Iguaçu, RS, Brasil, 22.

Gil, A. C. (2008). Métodos e técnicas de pesquisa social. São Paulo: Ed. Atlas S.A.

Gill, R. (2002). Análise do discurso. In: Bauer, M. W.; Gaskell, G. Pesquisa qualitativa com texto, imagem e som: um manual prático. Petrópolis: Vozes.

Godoi, C. K., \& Bandeira-de-Mello, R. (2006). Pesquisa qualitativa em estudos organizacionais: paradigmas, estratégias e métodos. São Paulo: Saraiva.

Jenkins, H. (2008). Cultura da convergência. São Paulo: Aleph. 
Kotler, P., Kartajaya, H., \& Setiawan, I. (2017). Marketing 4.0: Do tradicional ao digital. Rio De Janeiro: Sextante.

Markus, K., \& Orsi, D. F. O. (2016). Um estudo do consumo colaborativo no Brasil e nos Estados Unidos da América. Revista Organizações em Contexto, 12(24).

Martins, G. A., \& Theóphilo, C. R. (2009). Metodologia da investigação científica para ciências sociais aplicadas. 2.ed. São Paulo: Atlas.

Mazetti, H. M. (2009, Maio). Cultura participativa, espetáculo interativo: do "empoderamento" ao engajamento corporativo dos usuários de mídia. In Trabalho apresentado a Divisão temática de Comunicação Multimídia, no XIV Congresso de Ciências da Comunicação na Região Sudeste. Rio de Janeiro.

McCracken, G. (2003). Cultura \& Consumo: novas abordagens ao caráter simbólico dos bens e atividades de consumo. Rio de Janeiro: Mauad.

Menezes, U. (2018). Consumo Colaborativo: Um caminho para o desenvolvimento sustentável? Consumer Behavior Review, 2, 56-68.

Parmentier, M., \& Ficher, E. (2015). Things fall apart: The dynamics of brand audience dissipation. Journal of Consumer Research, 41(5), 1228-1251.

Patterson, P., Yu, T., \& de Ruyter, K. (2006, December) Understanding customer engagement in services. Advancing theory, maintaining relevance, Proceedings of ANZMAC 2006 conference, Brisbane; 2006. 4-6.

Pereira, C. M. P., Silva, A. C., Barth, M., \& Pacheco, J. (2015). Interação, engajamento e crowdsourcing: um estudo de caso The Johnny Casy Project. Comunicação \& Informação, 18(1), 76-96.

Phillipson, J., Gorton, M., \& Laschewski, L. (2006). Local business co-operation and the dilemmas of collective action: rural micro-business networks in the north of England. Sociologia Ruralis, $46(1), 40-60$.

Ritzer, G. (2015a). Hospitalidade e prossumerização. Revista Hospitalidade, 12 (edição especial), 12-41.

Ritzer, G. (2015b). Prosumer capitalismo. The Sociological Quarterly, 56, 413-445.

Ruckenstein, M. (2015). Playing Nintendogs: desire, distributed agency and potentials of prosumption. Journal of Consumer Culture, 15(3), 351-370.

Scaraboto, D. (2015). Selling, sharing, and everything in between: the hybrid economies of collaborative networks. Journal of Consumer Research, 42(1), 152-176.

SEBRAE (2019). Tudo o que você precisa saber sobre uma loja colaborativa. Recuperado em: 03 de fevereiro de 2020 de <https://www.sebrae.com.br/sites/PortalSebrae/artigos/lojacolaborativa-o-que-e-como-funciona-vantagens-e-comoparticipar,3a5a33e06c9cf510VgnVCM1000004c00210aRCRD>

Shirky, C. (2011). A cultura da participação: Criatividade e generosidade no mundo conectado. Rio de Janeiro: Zahar.

Silva, M., \& Barbosa, M. (2018). Compartilhando Bicicletas e Consumindo Experiências: Uma investigação do consumo colaborativo praticado por usuários do Bike PE. Consumer Behavior Review, 2, 1-18.

Silva, M. J. B., Barbosa, M. L. A., Costa, M. F., \& Gomes, J. P. (2020). Entre Posse e Acesso: Compreendendo a extensão do self no consumo colaborativo. Organizações \& Sociedade (online), In press.

Sousa Júnior, J. (2018). "Vai uma Carona, aí?": Experiências de consumo colaborativo de usuários de aplicativo de caronas. Consumer Behavior Review, 2, 33-42.

Stake, R. (2006). Multiple case study analysis. Nova Iorque: Guilford Press.

Wood, D. J., \& Gray, B. (1991). Toward a Comprehensive Theory of Collaboration. The Journal of Applied Behavioral Science, 27(2).

Zappellini, M. B., \& Feuerschütte, S. G. (2015). 0 uso da triangulação na pesquisa científica brasileira em Administração. Administração: Ensino e Pesquisa, 16(2), 241-273. 